Article received 04.09.2019 p.

Article accepted 26.09.2019 p.

$@ \bowtie$ Correspondence author

I. Ye. Ivashchenko

удК630*582.477

ivashchenko_iy@ukr.net

I. Є. Іващенко

Уманський національний університет садівництва, м. Умань, Україна

\title{
КУЛЬТИВАРИ ВИДУ ТНUJА РLICATA DONN EX D. DON У ПРАВОБЕРЕЖНОМУ ЛICОСТЕПУ УКРАЇНИ ТА МОЖЛИВОСТІ ЇХ ВИКОРИСТАННЯ В САДОВО-ПАРКОВОМУ БУДІВНИЦТВІ
}

\begin{abstract}
Досліджено внутрішньовидове різноманіття виду Thuja plicata Donn ex D. Don у Правобережному Лісостепу України. Встановлено, що із 54 відомих культиварів виду в дендрологічних парках регіону вже багато років успішно зростають два: Th. p. 'Zebrina' i Th. p. 'Aureovariegata'. За останні 10 років також були введені Th. $p$. 'Dura' та Th. $p$. 'Whipcord'. У декоративному садівництві поширені такі культивари Th. plicata: Th. $p$. 'Atrovirens', Th. $p$. 'Aureovariegata', Th. $p$. 'Can-Can', Th. $p$. 'Daniellow', Th. $p$. 'Dura', Th. $p$. 'Excelsa', Th. $p$. 'Gelderland', Th. $p$. 'Goldy', Th. $p$. 'Kornik', Th. $p$. 'Whipcord', Th. $p$. 'Zebrina' та Th. p. 'Zebrina Extra Gold'. Для характеристики різноманіття культиварів Th. plicata, що ростуть у Правобережному Лісостепу України, використано систему класифікації формового складу поліваріантних видів Р. В. Кармазіна. Згідно $з$ цією класифікацією, досліджувані рослини Th. plicata належать до надгрупи В (рослини з лускоподібною хвоєю). Із 12 культиварів до групи I віднесено шість; до групи II - три; до групи III - три. Визначено біометричні показники досліджуваних культиварів. Виділено культивари Th. plicata, які поширені в районі досліджень за найбільш істотними декоративними ознаками, а саме: за забарвленням хвої, формою крони та висотою (низькорослі форми). Враховуючи їхні декоративні якості, надано рекомендації щодо застосування у різних типах насаджень: солітерах, групах, алеях, живоплотах, під час створення альпінаріїв та контрастних композицій.
\end{abstract}

Ключові слова: інтродукція; декоративність; архітектоніка крони; ландшафтна композиція; альпінарій.

Вступ. Проблема оптимізації асортименту деревних і кущових рослин, що використовуються для побудови ландшафтних композицій, сьогодні є актуальною. Велика роль у формуванні культурних фітоландшафтів належить рослинам-інтродуцентам. Внутрішньовидове різноманіття Th. plicata є цінним і перспективним матеріалом для створення високохудожніх садово-паркових композицій (Kuznetsov, Marinich, Pohilchenko \& Slyusar, 2003).

В озелененні України рослини Th. plicata використовують рідко, на відміну від інших європейських країн, де їх високо цінують у садово-парковому господарстві та часто культивують у парках і великих садах. Як декоративне дерево, вид часто використовують у Середній і Північній Атлантиці США, Південній Австралії, Великобританії та Швейцарії. Дуже добре почувається у вуличних насадженнях Шотландії, Німеччини, Італії та Франції. У Нідерландах його переважно використовують в озелененні присадибних ділянок (Minor, 1990; Aksenova \& Frolova, 1987; Doroshenko, 1980).

Представники Th. plicata $є$ цінним рослинним матеріалом для створення ландшафтних композицій як у пейзажному, так і в регулярному стилях. Окрім цього, вони не потребують особливого догляду впродовж року і мають привабливий декоративний вигляд. У літній період рослини виду контрастують із листяними деревами й чагарниками і вигідно підкреслюють одне одного, будучи ідеальним матеріалом для побудови композицій на підставі контрастів форм та забарвленні хвої. У зимовий - створюють основу саду, чітко виділяючись на фоні білого снігу.

Мета дослідження - визначити внутрішньовидове різноманіття виду Thuja plicata у Правобережному Лісостепу України та надати рекомендації щодо його використання для створення садово-паркових композицій.

Об'єкт дослідження - культивари виду Thuja plica$t a$, що зростають у Правобережному Лісостепу України.

Методи дослідження. Таксономічний склад об'єктів досліджень уточнювали згідно $з$ даними Royal Horticultural Society (2019).

Для характеристики формового складу використали систему класифікації формового складу поліваріантних видів Р. В. Кармазіна (1968), а саме:

- А. Ювенільні форми - 3 голкоподібною (ювенільною) хвоєю.

- Б. Перехідні форми - 3 хвоєю проміжного типу (або рослина має хвою обох типів).

В. 3 лускоподібною хвоєю, тобто 3 хвоєю дорослої рослини. Надгрупа "В" підрозділяється на три групи: I. Ростова - форми з відхиленнями від типу у величині росту (у дорослих особин), формі крони, характеру галуження пагонів різного порядку, морфології пагонів. II. Колірно-ростова - форми з ознаками ростової групи, але, окрім цього, вони мають відхилення у забарвленні або відтінку хвої та пагонів, які можуть бути постійними (стійкими) або сезонними (мінливими). III. Колір-

Інформація про авторів:

Іващенко Ірина Євгеніївна, канд. с.-г. наук, доцент, кафедра лісового господарства. Email: ivashchenko_iy@ukr.net

Цитування за ДСту: Іващенко I. Є. Культивари виду Thuja plicata Donn ex D. Don у Правобережному Лісостепу України та можливості їх використання в садово-парковому будівництві. Науковий вісник Нлту України. 2019, т. 29, № 7. С. 27-30.

Citation APA: Ivashchenko, I. Ye. (2019). Cultivars of Thuja plicata Donn ex d. Don in the Right Bank Forest Steppe of Ukraine and Their Possibility to use in Garden Building. Scientific Bulletin of UNFU, 29(7), 27-30. https://doi.org/10.15421/40290705 
на - форми з відхиленням від типу тільки в забарвленні хвої та пагонів. Першу та другу групи розділено на три підгрупи росту: 1 - нормального росту, 2 - середньорослі та 3 - низькорослі, кожна 3 яких поділяється на варіації: а) відхилення за формою крони: колоновидноподібні, пірамідальні, кулясті; б) відхилення за формою крони та будовою пагонів і хвої або в характері галуження: плакучі, розпростерті.

Результати дослідження та їх обговорення. Внутрішньовидове різноманіття Th. plicata вивчали такі вченi: Blyakharska \& Wikluk, 2012; Bulygin \& Yarmyshko, 2003; Grodzinsky, 1980; Kalinichenko, 2003; Kaplunenko, 1968; Kokhno, 2005; Lypa, 1978; Zayachuk, 2005. Опрацювання результатів їх досліджень дало змогу встановити біометричні показники досліджених у статті культиварів.

Загалом, за даними Royal Horticultural Society (2019), Th. plicata має 54 культивари, 3 яких у дендрологічних парках України вже багато років успішно зростають два: Th. p. 'Zebrina' i Th. p. 'Aureovariegata' (Dendrosozologicheskiy catalog, 2011; Kolb, 2011). За останні 10 років також було введено Th. p. 'Dura' та Th. p. 'Whipcord'. У декоративному садівництві України поширені такі культивари Th. plicata: Th. p. 'Atrovirens', Th. p. 'Aureovariegata', Th. p. 'Can-Can', Th. p. 'Daniellow', Th. p. 'Dura', Th. p. 'Excelsa', Th. p. 'Gelderland', Th. p. 'Goldy', Th. p. 'Kornik', Th. p. 'Whipcord', Th. p. 'Zebrina' та Th. p. 'Zebrina Extra Gold'. Однак більшість 3 них зростає на приватних присадибних ділянках, хоча за своїми декоративними ознаками заслуговують на ширше використання в садово-парковому будівництві.

Для характеристики різноманіття культиварів Th. plicata, що зростають у Правобережному Лісостепу Ук- раїни, використано систему класифікації формового складу поліваріантних видів Р. В. Кармазіна (1968) (табл. 1).

Табл. 1. Класифікація формового складу Th. plicata (за Р. В. Кармазіним)

\begin{tabular}{|c|c|c|c|c|}
\hline $\begin{array}{c}\text { Над- } \\
\text { група }\end{array}$ & Група & Підгрупа & $\begin{array}{c}\text { Bapi- } \\
\text { ація } \\
\end{array}$ & Культивар \\
\hline \multirow{13}{*}{ B } & \multirow{6}{*}{$\begin{array}{c}\mathrm{I} \\
\text { (росто- } \\
\text { ва) }\end{array}$} & \multirow{2}{*}{$\begin{array}{l}\text { 1. Нормального } \\
\text { росту }\end{array}$} & A & $\begin{array}{l}\text { Th. p. 'Excelsa' } \\
\text { Th. p. 'Kornik' }\end{array}$ \\
\hline & & & Б & Th. p. 'Dura' \\
\hline & & \multirow{2}{*}{$\begin{array}{l}\text { 2. Середньорос- } \\
\text { лі }\end{array}$} & $\mathrm{A}$ & - \\
\hline & & & Б & - \\
\hline & & \multirow{2}{*}{ 3. Низькорослі } & A & Th. p. 'Can-Can' \\
\hline & & & Б & Th.p. 'Whipcord' \\
\hline & \multirow{6}{*}{$\begin{array}{l}\text { II } \\
\text { (колір- } \\
\text { но-рос- } \\
\text { това) }\end{array}$} & \multirow{2}{*}{\begin{tabular}{|l|} 
1. Нормального \\
росту
\end{tabular}} & $\mathrm{A}$ & - \\
\hline & & & Б & Th. p. 'Gelderland' \\
\hline & & \multirow{2}{*}{ 2. Середньорос- } & A & $\begin{array}{c}\text { Th. p. 'Atrovirens' } \\
\text { Th. p. 'Goldy' }\end{array}$ \\
\hline & & & 5 & - \\
\hline & & \multirow{2}{*}{ 3. Низькорослі } & $\mathrm{A}$ & - \\
\hline & & & Б & Th. p. 'Danielow' \\
\hline & $\begin{array}{l}\text { III } \\
\text { (колір- } \\
\text { на) }\end{array}$ & - & - & $\begin{array}{c}\text { Th. } p . \text { 'Aureovariegata' } \\
\text { Th. } p \text {. 'Zebrina' } \\
\text { Th. p. 'Zebrina Extra } \\
\text { Gold' } \\
\end{array}$ \\
\hline
\end{tabular}

Згідно з цією класифікацією, досліджувані культивари Th. plicata належать до надгрупи В (рослини з лускоподібною хвоєю). До ростової групи (I) віднесено культивари Th. p. 'Excelsa', Th. p. 'Kornik', Th. p. 'Dura', Th. p. 'Can-Can' i Th. p. 'Whipcord'; до колірно-ростової (II) - Th. p. 'Gelderland', Th. p. 'Atrovirens', Th. p. 'Goldy' i Th. $p$. 'Danielow'; до колірної (III) - Th. p. 'Aureovariegata', Th. $p$. 'Zebrina' та Th. $p$. 'Zebrina Extra Gold'.

Біометричні показники перспективних для вирощування культиварів Th. plicata представлені в табл. 2.

Табл. 2. Біометричні показники культиварів Th. plicata

\begin{tabular}{|c|c|c|c|c|}
\hline № $3 / \Pi$ & Культивар & Висота дерева, м & Проекція крони, м & Форма крони \\
\hline 1 & Th.p. 'Atrovirens' & $12,0-15,0$ & $3,0-5,0$ & Колоноподібна \\
\hline 2 & Th. p. 'Aureovariegata' & $12,0-15,0$ & $3,0-5,0$ & Конусоподібна \\
\hline 3 & Th. p. 'Can-Can' & $1,2-1,5$ & $1,2-1,5$ & Конусоподібна \\
\hline 4 & Th. p. 'Danielow' & $1,2-1,5$ & $0,8-1,2$ & Конусоподібна \\
\hline 5 & Th. p. 'Dura' & $7,0-8,0$ & $2,0-3,0$ & Колоноподібна \\
\hline 6 & Th.p. 'Excelsa' & $12,0-15,0$ & $3,0-5,0$ & Колоноподібна \\
\hline 7 & Th. p. 'Gelderland' & $15,0-17,0$ & $3,0-5,0$ & Колоноподібна \\
\hline 8 & Th. p. 'Goldy' & $2,0-2,5$ & $1,3-1,5$ & Конусоподібна \\
\hline 9 & Th.p. 'Kornik' & $5,5-6,0$ & $4,0-6,0$ & Пірамідальна \\
\hline 10 & Th. p. 'Whipcord' & $0,5-1,0$ & $1,0-1,5$ & Плакуча \\
\hline 11 & Th.p. 'Zebrina' & $12,0-15,0$ & $4,0-6,0$ & Ширококуляста \\
\hline 12 & Th. p. 'Zebrina Extra Gold' & $12,0-15,0$ & $4,0-6,0$ & Конусоподібна \\
\hline
\end{tabular}

Досліджуючи культивари Th. plicata, варто відзначити їхню різноманітність за формами крони, забарвленням хвої та розмірами. Ці відмінності надають рослинам виразність і декоративність та відкривають великі можливості під час формування різноманітних ландшафтних композицій.

Виділено культивари Th. plicata, які поширені в районі досліджень за найбільш істотними декоративними ознаками, а саме: за забарвленням хвої, формою крони та висотою (низькорослі форми) (табл. 3).

Культивари Th. p. 'Aureovariegata' i Th. p. 'Zebrina' зростають переважно як солітери (рисунок). Характеризуються високою декоративністю упродовж року та гарним санітарним станом. На фоні інших рослин вони виділяються чіткою архітектонікою крони. У літній період року їхня хвоя набуває насиченого забарвлення, що вигідно виділяє їх серед інших рослин.
Табл. 3. Поділ культиварів Th. plicata за декоративними ознаками

\begin{tabular}{|c|c|c|}
\hline \multicolumn{3}{|c|}{ Найбільш характерні групи декоративних ознак } \\
\hline забарвлення хвої & форма крони & $\begin{array}{c}\text { висота (низькорос- } \\
\text { лі форми) }\end{array}$ \\
\hline $\begin{array}{l}\text { Th. p. 'Aureovariegata' } \\
\text { Th. p. 'Gelderland' } \\
\text { Th. p. 'Goldy' } \\
\text { Th. p. 'Zebrina' } \\
\text { Th. p. 'Zebrina Extra } \\
\text { Gold' }\end{array}$ & $\begin{array}{c}\text { Th. p. 'Atrovirens' } \\
\text { Th. p. 'Dura' } \\
\text { Th. p. 'Kornik' } \\
\text { Th. p. 'Excelsa' }\end{array}$ & $\begin{array}{l}\text { Th. p. 'Can-Can' } \\
\text { Th. p. 'Daniellow' } \\
\text { Th. p. 'Whipcord' }\end{array}$ \\
\hline
\end{tabular}

Культивари 3 яскравим забарвленням хвої застосовують для створення контрастних композицій та яскравих поодиноких насаджень. Вони виглядають особливо ефектно на добре освітлених місцях. До цієї підгрупи віднесли такі культивари Th. plicata: Th. p. 'Aureovariegata', Th. p. 'Gelderland', Th. $p$. 'Goldy', Th. $p$. 'Zebrina' та Th. p. 'Zebrina Extra Gold'. Дерева 3 чітко вираженою компактною формою крони є чудовим матеріалом для створення контрастних архітектурних композицій. 

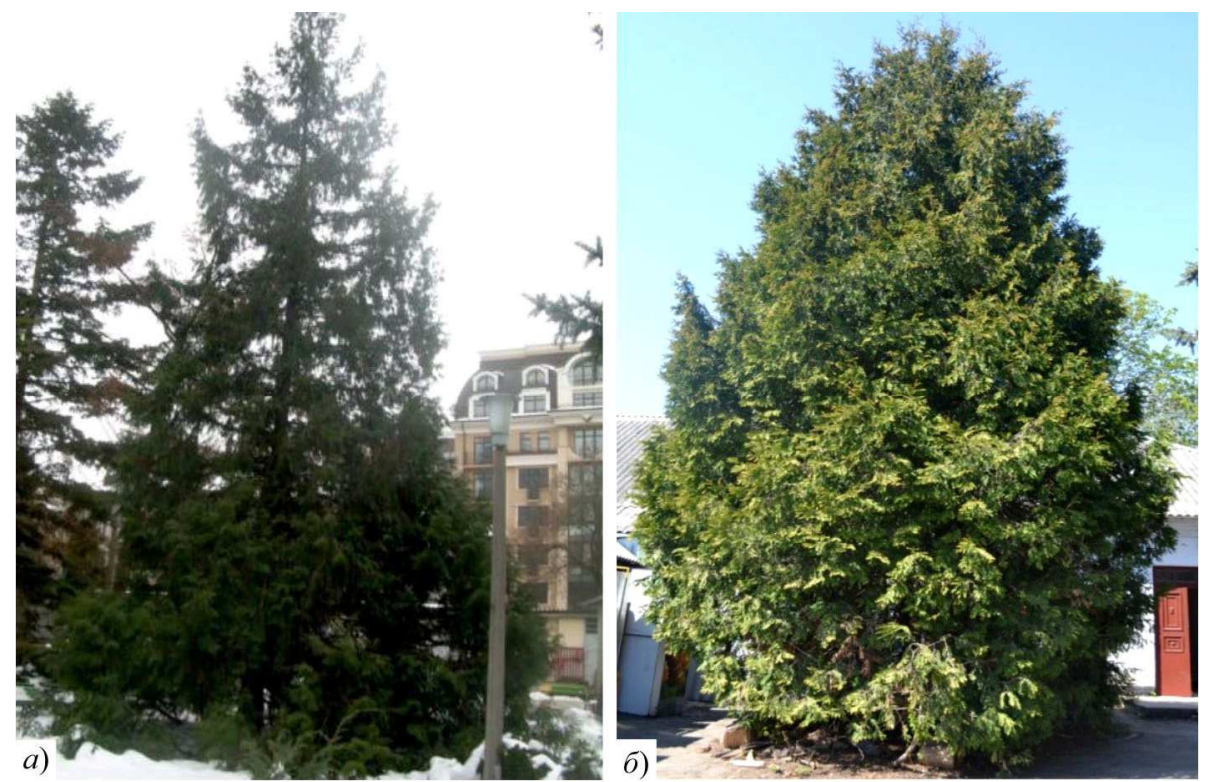

Рисунок. Культивари Th. plicata: a) Th. p. 'Zebrina' (Ботанічний сад ім. акад. О. В. Фоміна Київського національного університету ім. Тараса Шевченка); б) Th. p. 'Aureovariegata' (Національний дендрологічний парк "Софіївка" НАН України) (фото автора)

Вони особливо цінні на невеликих ділянках. До таких віднесено Th. $p$. 'Dura', Th. $p$. 'Kornik' та Th. $p$. 'Excelsa'. Низькорослі рослини переважно використовують під час створення різноманітних типів альпінаріїв. До таких належать: Th. $p$. 'Can-Can', Th. $p$. 'Daniellow' та Th. p. 'Whipcord'.

Згідно з проведеними обстеженнями в дендрологічних садах та парках Правобережного Лісостепу України, виявлено, що вид Th. plicata використовують у групових і поодиноких насадженнях, алеях та контрастних композиціях. Оскільки вид Th. plicata та його культивари $є$ стійкими до стрижки, з них доцільно створювати зелені стіни, які розділяють простір на "кімнати", формувати геометричні фігури у вигляді поодиноких або групових насаджень та живі огорожі. Штучне формування рослин виду дасть змогу частіше застосовувати їх під час створення регулярних композицій, а також ефектних живоплотів.

Табл. 4. Використання Th. plicata та їі культиварів у різних типах насаджень

\begin{tabular}{|c|c|c|c|c|c|c|c|c|}
\hline \multirow[b]{2}{*}{$\begin{array}{l}\text { № } \\
\text { 3/ח }\end{array}$} & \multirow[b]{2}{*}{ Культивар } & \multicolumn{7}{|c|}{ Тип насаджень } \\
\hline & & 志 & 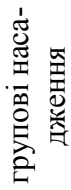 & 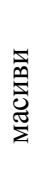 & $\begin{array}{l}\overline{\bar{\Phi}} \\
\text { క్త }\end{array}$ & 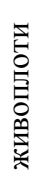 & 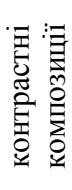 & $\begin{array}{l}:= \\
\text { 芯 } \\
\text { 茵 } \\
\text { 量 }\end{array}$ \\
\hline 1 & Th. plicata & + & + & + & + & + & - & - \\
\hline 2 & Th.p. 'Atrovirens' & - & - & - & - & + & + & - \\
\hline 3 & Th. $p$. 'Aureovariegata' & + & + & - & + & + & + & - \\
\hline 4 & Th. p. 'Can-Can' & - & - & - & - & + & + & + \\
\hline 5 & Th. p. 'Daniellow' & - & - & $\begin{array}{llll}- & \\
\end{array}$ & - & + & + & + \\
\hline 6 & Th. p. 'Dura' & - & + & - & + & + & - & - \\
\hline 7 & Th. p. 'Excelsa' & - & + & - & + & + & - & - \\
\hline 8 & Th. p. 'Gelderland' & - & + & - & + & + & + & - \\
\hline 9 & Th. p. 'Goldy' & - & - & - & - & + & + & + \\
\hline 10 & Th. p. 'Kornic' & + & + & - & - & + & - & - \\
\hline 11 & Th.p. 'Whipcord' & - & - & - & - & - & - & + \\
\hline 12 & Th.p. 'Zebrina' & + & + & - & + & + & + & - \\
\hline 13 & Th. p. 'Zebrina Extra Gold' & + & + & - & + & + & + & - \\
\hline
\end{tabular}

Окрім цього, колоноподібні й пірамідальні форми Th. plicata підкреслюють архітектуру, тому їх доцільно висаджувати біля входу до парку чи скверу, на меморі- алах біля пам'ятників і стел, поєднувати 3 колонами та скульптурами. Також рослини Th. plicata можна використовувати з метою "маскування", щоб закривати небажані види, паркани, будівельні й господарські будівлі.

Проаналізувавши колекції ботанічних садів і парків та каталоги садових центрів, визначено, що в Україні сьогодні поширені 12 культиварів Th. plicata. 3 метою ix ширшого впровадження в садово-паркове будівництво надано рекомендації щодо їх використання у різних типах насаджень (табл. 4).

Встановлено, що досліджені рослини Th. plicata можна часто використовувати в різноманітних типах насаджень. Вид Th. plicata можна застосовувати в поодиноких та групових насадженнях, масивах, як солітер, а також під час створення алей і живоплотів. Для формування живоплотів можна використовувати всі культивари Th. plicata, окрім Th. p. 'Whipcord', який доцільно застосовувати для створення альпійських ландшафтів. Як солітери доцільно використовувати вид та його культивари Th. $p$. 'Aureovariegata', Th. $p$. 'Zebrina'та Th. p. 'Zebrina Extra Gold', оскільки вони акцентують увагу на ландшафтну композицію не тільки своєю формою крони, а й яскравим забарвленням хвої. Для групових насаджень рекомендуємо використовувати вид та його культивари Th. $p$. 'Aureovariegata', Th. $p$. 'Dura', Th. p. 'Excelsa', Th. p. 'Gelderland', Th. $p$. 'Zebrina' та Th. $p$. 'Zebrina Extra Gold'. Для створення алей необхідно враховувати архітектоніку крони рослин. Бажаним рослинним матеріалом $є$ форми 3 колоноподібною та конічною кроною, такі як: Th. $p$. 'Aureovariegata', Th. $p$. 'Dura', Th. $p$. 'Excelsa', Th. $p$. 'Gelderland', Th. $p$. 'Zebrina' та Th. $p$. 'Zebrina Extra Gold'. За створення контрастних композицій головною особливістю $€$ підбір рослин 3 яскравим забарвленням хвої чи листя. Серед внутрішньовидового різноманіття Th. plicata виділено культивари з яскравим забарвленням хвої, а саме: Th. $p$. 'Atrovirens', Th. $p$. 'Aureovariegata', Th. $p$. 'Can-Can', Th. p. 'Daniellow', Th. p. 'Gelderland', Th. p. 'Goldy', Th. p. 'Zebrina' та Th. $p$. 'Zebrina Extra Gold'. Для створення альпінаріїв необхідно підбирати низькорослі форми. Серед досліджуваних культиварів Th. plicata такими $\epsilon$ Th. p. 'Can-Can', Th. p. 'Daniellow' тa Th. p. 'Whipcord'. 
Результати виконаних досліджень свідчать про те, що інтродукований вид Th. plicata та його значне внутрішньовидове різноманіття $\epsilon$ надзвичайно перспективними для створення ландшафтних композицій у Правобережному Лісостепу України. Основними цінними властивостями Th. plicata $\epsilon$ декоративність упродовж року, довговічність та здатність витримувати стрижку.

\section{Висновки:}

1. Внутрішньовидове різноманіття Th. plicata у досліджених умовах представлено культиварами Th. $p$. 'Aureovariegata' та Th. p. 'Zebrina'. Для озеленення населених пунктів вид практично не використовують, хоча за своїми декоративними якостями заслуговує частішого впровадження.

2. Нині в декоративному садівництві України зростають такі культивари Th. plicata: Th. p. 'Atrovirens', Th. p. 'Aureovariegata', Th. $p$. 'Can-Can', Th. $p$. 'Daniellow', Th. $p$. 'Dura', Th. p. 'Excelsa', Th. $p$. 'Gelderland', Th. $p$. 'Goldy', Th. p. 'Kornik', Th. p. 'Whipcord', Th. p. 'Zebrina' та Th. p. 'Zebrina Extra Gold'.

3. У класифікації формового складу поліваріантних видів культивари Th. plicata віднесено до надгрупи В. До групи I віднесено 6 з них; до групи II - 3; до групи III - 3 .

4. Рослини Th. plicata, що культивуються на території Правобережного Лісостепу України, можна часто використовувати в різноманітних типах насаджень, а саме: солітерах, групах, алеях, живоплотах, під час створення альпінаріїв та контрастних композицій.

\section{Перелік використаних джерел}

Aksenova, N. A., \& Frolova, L. A. (1987). Intraspecific differences in coniferous introducers. GBS Bulletin, 145, 15-21. Moscow: Science. [In Russian].

Blyakharska, L. O., \& Wikluk, M. I. (2012). Analysis of the Thuja L. genus of the Botanical Garden of ChNU im. Y. Fedkovicha. Science visnik of ChNU, 455, 6-8. [In Ukrainian].

Bulygin, N. E., \& Yarmyshko, V. T. (2003). Dendrology. Moscow: MGUL, 528 p. [In Russian].
Doroshenko, O. K. (1980). Wood decorative ornaments of Western and Right Bank Forest-Steppe of Ukraine. Introduction and acclimatization of plants in Ukraine, 16, 15-22. [In Ukrainian].

Grodzinsky, A. M. (1980). Plant introduction during the period of the scientific and technological revolution. Theories and methods of plant introduction and green building, 3-6. Kiev. [In Ukrainian].

Kalinichenko, O. A. (2003). Decorative dendrology. Kiev, 199 p. [In Ukrainian].

Kaplunenko, M. F. (1968). Thuja and biota eastern in landscaping in Ukraine. Kiev: Science opinion, 88 p. [In Ukrainian].

Karmazin, R. V. (1968). Formal composition of Thuja occidentalis L. in the western regions of Ukraine and questions of its classification. Bulletin of the main botanical garden, 70, 60-73. [In Ukrainian].

Kokhno, M. A., \& Kuznetsov, S. I. (2005). Methodical recommendations for adding a tree and bushes for industrial production in Ukraine. Kiev: Phytosociocenter, 48 p. [In Ukrainian].

Kokhno, M. A., Parkhomenko, L. I., Zarubenko, A. U., \& Vakhnovska, N. G. (2002). Dendroflora of Ukraine. Wild and cultivated tree and bush. Kiev: Phytosociocenter, 426 p. [In Ukrainian].

Kolb, V. A. (2011). Introducing decorative ornaments for using in greenery in the minds of Left Bank Forest-Steppe of Ukraine. Bulletin of the Nikitsky Botanical Garden, 100, 51-55. [In Ukrainian].

Kuznetsov, S. I., Marinich, I. S., Pohilchenko, O. P., \& Slyusar, S. I. (2003). Coniferous biodiversity in collection and park crops-phytocenoses in connection with their introduction in Polesie and the Forest-Steppe of Ukraine. Bulletin State Nikitsky Botanical Garden, 88, 106. Yalta. [In Ukrainian].

Lypa, A. L. (1978). Introduction and acclimatization of woody plants in Ukraine. Kiev: Higher school, 112 p. [In Ukrainian].

Minor, D. (1990). Thuja folded Donn ex D. Don Western cedar. Silvics of North America. Coniferous trees. Washington, $654 \mathrm{p}$.

Popovich, S. Yu. (Ed.). (2011). Dendrosozologicheskiy catalog of the natural reserve fund Forest-Steppe of Ukraine. Kiev: Agrar Media Group, 800 p. [In Ukrainian].

Search the RHS Horticultural Database. (2019). Royal Horticultural Society. Retrieved from: http://apps.rhs.org.uk/horticulturaldatabase/summary2.asp?crit=thuja + and + plicata\&Genus $=$ Thuja

Zayachuk, V. Ya. (2005). Dendrology: Holonasinni. Lviv: Kamula, 176 p. [In Ukrainian].

\section{Ye. Ivashchenko \\ Uman National University of Horticulture, Uman, Ukraine}

\section{CULTIVARS OF THUJA PLICATA DONN EX D. DON IN THE RIGHT BANK FOREST STEPPE OF UKRAINE AND THEIR POSSIBILITY TO USE IN GARDEN BUILDING}

Investigated a intraspecies diversity of Thuja plicata Donn ex D. Don species in the Right-bank Forest Steppe of Ukraine. It has been established that two of 54 known cultivars of the species in the dendrological parks of the region have been successfully growing for many years. They are as follows: Th. $p$. 'Zebrina' and Th. $p$. 'Aureovariegata'. Over the past 10 years, the next decorative forms have also been introduced: Th. $p$. 'Dura' and Th. $p$. Whipcord. In ornamental horticulture are common such cultivars as Th. plicata: Th. p. 'Atrovirens', Th. p. 'Aureovariegata', Th. p. 'Can-Can', Th. p. 'Daniellow', Th. p. 'Dura', Th. p. 'Excelsa', Th. $p$. 'Gelderland', Th. $p$. 'Goldy', Th. $p$. 'Kornik', Th. $p$. 'Whipcord', Th. $p$. 'Zebrina' and Th. $p$. 'Zebra Extra Gold'. Exploring the cultivars of Th. plicata, we should note their variety in crown shapes, conifer colour and size. These differences give the plants expressiveness and decorativeness, and also open up great opportunities in the formation of various landscape compositions. For characterization of the variety of cultivars Th. plicata growing in the Right-bank Forest Steppe of Ukraine, we used the system of classification of the composition of the multivariate species of R. V. Karmazin. According to this classification, the investigated plants Th. plicata belong to the group B (plants with scaly needles). Of the 12 cultivars in group I we assigned six; II - three; III - three. The authors have determined the biometric parameters of the cultivars under study. The cultivars of Th. plicata are widespread in the study area by the most significant decorative features, namely: the needles, crown shape, and height (stunted). Considering their decorative qualities, the following recommendations for use in different types of plantings are given: alone, groups, alleys, hedges, when creating rock gardens and contrast compositions. The results of the studies indicate that the introduced species Th. plicata and its considerable intraspecific diversity are extremely promising for the creation of landscape compositions in the Right-bank Forest Steppe of Ukraine. The main valuable properties of Th. plicata are a year-round decorative feature, durability and ability to withstand a haircut.

Keywords: introduction; decorative; architectonics of the crown; landscape composition; rock garden. 